\title{
Paramedicine students' views on clinical placement learning using the DREEM inventory
}

\author{
Brett Williams *1, Peter O'Meara ${ }^{2}$, Helen Hickson ${ }^{2}$ \\ ${ }^{1}$ Monash University, Melbourne, Victoria, Australia \\ ${ }^{2}$ LaTrobe University, Melbourne, Victoria, Australia
}

Received: September 14, 2015

Accepted: October 14, 2015

Online Published: October 28, 2015

DOI: $10.5430 /$ jnep.v6n2p35

URL: http://dx.doi.org/10.5430/jnep.v6n2p35

\begin{abstract}
Introduction: Popularity of paramedicine undergraduate programs continues to rise in Australia and New Zealand. While this is important in the professionalisation of paramedicine, it has also raised a number of issues, particularly those surrounding the issue of national clinical placement standards and consistency between university providers. Therefore the purpose of this cross-sectional study was to investigate paramedicine student perceptions of the learning environment during their university studies.

Methods: The Dundee Ready Education Environment Measure (DREEM) is a validated questionnaire that measures students' perceptions of the educational environment. Convenience sampling was used to recruit 682 undergraduate paramedicine students enrolled at five universities in Australia and New Zealand.

Results: This study has investigated the education environment as perceived by paramedicine students and found that generally, students were satisfied with the education environment at their institution. There were 630 student participants from Australia and 52 from New Zealand.

Conclusions: The DREEM questionnaire has highlighted significant differences between universities, which is not surprising considering the various ways that universities structure their paramedicine programs. These findings can be used to inform universities and ambulance services about these differences and to guide strategic planning to ensure that there is a more consistent approach to paramedicine education in Australia and New Zealand.
\end{abstract}

Key Words: Clinical education, Paramedicine, Dundee Ready Education Environment Measure

\section{INTRODUCTION}

There have been significant changes for the paramedicine profession in Australian and New Zealand; no longer reliant on vocational education and training it has moved a long way towards professionalisation in its quest of developing an esoteric body of knowledge through university-based qualifications. ${ }^{[1-4]}$ There are now 17 universities in Australia and New Zealand that offer a pre-employment Bachelor degree program as a pathway to paramedicine practice. ${ }^{[5,6]} \mathrm{In}$
Australia and New Zealand, there is much diversity in the structure and content of the paramedicine qualification programs, with undergraduate courses ranging from 3 to 4 years in duration, with options for single and double degree qualifications, post-graduate conversion programs for nurses and other health professionals, and significant variation in the focus and duration of clinical education. ${ }^{[7]}$ Whilst the diversity between university providers might stem from innovation, it also brings inconsistency and disparity in the preparedness

*Correspondence: Brett Williams; Email: brett.williams@ monash.edu; Address: Monash University, Melbourne, Victoria, Australia. 
of students for paramedicine clinical placement. ${ }^{[8,9]}$

In Australia and New Zealand, clinical education for paramedicine students can take many different forms. ${ }^{[10]}$ There are currently no standards or requirements for the number of hours of clinical placement, where they should be located nor how quality should be measured. As a result, there is much variation between universities in the number of hours of clinical placement, which year of study they are linked with, whether placements are situated in the ambulance service, hospital, pre-hospital or community setting, and whether placement hours include simulated clinical experiences. ${ }^{[7]}$

Research exists in paramedicine related to student perceptions of the learning environment using a variety of different measurement tools. ${ }^{[2,9-15]}$ This study used the Dundee Ready Education Environment Measure (DREEM) survey instrument to investigate and compare perceptions of the educational environment from paramedicine students at five universities. The aim of this study was to evaluate the education environment as perceived by paramedicine students in Australia and New Zealand. This research is part of a larger study titled: "Paramedicine clinical placement duration and quality variance: An international benchmarking study". ${ }^{[7]}$ To the best of our knowledge this is the first study that attempts to examine paramedicine clinical placements across two countries.

\section{Method}

Paramedicine students at five institutions that offer entrylevel paramedicine courses in Victoria, Australia and Auckland, New Zealand were invited to participate in this study: Auckland University of Technology (AUT), Australian Catholic University (ACU), Monash University (MU), La Trobe University (LTU), and Victoria University (VU). These institutions were selected due to the diversity of their program structure, including variety in clinical placement duration, content and structure.

\subsection{Design}

A cross-sectional survey design was used with a paper-based questionnaire with a standardised self-report scale. A short demographic questionnaire was designed to collect information such as the student's age, gender, year of study and institution.

\subsection{Participants}

Participants included 682 paramedicine students enrolled in an entry-level paramedicine course at the targeted institutions. Courses are three or four years in length. Convenience sampling was used to source participants from each university.
Inclusion criteria for participants were being enrolled in an entry-level paramedicine course in Victoria or New Zealand and having completed at least one clinical placement.

\subsection{Instrumentation}

The DREEM is a validated, generic instrument that is used to measure students' perceptions of the education environment. ${ }^{[16]}$ It can be used to make comparisons both within and between institutions or cohorts. ${ }^{[17]}$ This survey was originally developed to evaluate the changing educational environment and has been translated and used internationally to measure the learning and teaching climate and to compare experiences within the educational environment. ${ }^{[18,19]}$ The DREEM has 50 statements which are in five sub-scales: Students' perception of learning (12 items; min 12-max 60); Students' perceptions of teachers (11 items; min 11-max 55); Students' academic self-perceptions (8 items; min 8-max 40); Students' perceptions of atmosphere (12 items; min 12-max 60) and Students' social self-perceptions (7 items; $\min 7-\max 35)$. Each of the 50 statements is scored on a five-point scale, with the following labels: "Strongly agree", "Agree", "Not sure", "Disagree" and "Strongly disagree"; a higher score reflects stronger perceptions to that particular item and subscale. The DREEM has been shown to be valid and reliable in several contexts with medical and health care professions. ${ }^{[16,20]}$

\subsection{Procedures}

This research was conducted during 2013. At the end of a class (lecture or practical workshop), one of the researchers or a non-teaching member of staff facilitated the process by providing participants with an explanatory statement outlining the study and explaining that all data collected is anonymous. The DREEM and demographic questionnaires were distributed and consent to participate in this study was assumed if the student completed and returned the questionnaire. Students were able to leave if they did not wish to participate. Students completed the survey in about 10 minutes by marking their answers on the survey instrument. No follow-ups were undertaken.

Ethics approval for this research was granted by La Trobe University Human Research Ethics Committee (HREC), reference FHEC12/182, as well as the HREC for each participating university. As part of ethical approval, all participating universities are not to be acknowledged; only as Uni 1, Uni 2 etc.

\subsection{Data analysis}

DREEM scores and demographic data were entered into Statistical Package for the Social Sciences (SPSS) Version 20. 
Data were analysed using SPSS 20 and we present frequencies demographic data. Non-parametric analyses (Median scores $=\mathrm{Md}$, and interquartile ranges $=\mathrm{IQR}$ ) were used due to unequal cohort sizes (Mann-Whitney U Test; Kruskal-Wallis Test) and the results are statistically significant if $p<.05$.

\section{RESUlts}

\subsection{Participant demographics}

Table 1 shows the number and percentage of participants by gender, age group, university and year-level of enrolment. In addition to these figures, it was noted that most participants $(67.4 \%)$ identified that they lived in the city (included inner or outer city), with one quarter of participants identifying that they lived in a rural or semi-rural location.

Table 1. Demographic information of participants in 2013 $(\mathrm{n}=682)$

\begin{tabular}{lll}
\hline Variable & $\mathbf{N}$ & $\mathbf{( \% )}$ \\
\hline Gender & 279 & 40.9 \\
Male & 402 & 58.9 \\
Female & 1 & 0.2 \\
Undisclosed & & \\
Age & 80 & 11.7 \\
< 20 years & 378 & 55.4 \\
20-24 years & 141 & 20.7 \\
25-29 years & 37 & 5.4 \\
30-34 years & 23 & 3.4 \\
35-39 years & 23 & 3.4 \\
40 years or older & 109 & \\
Number of students from each University & 16.0 \\
Uni 1 & 25 & 3.7 \\
Uni 2 & 369 & 54.1 \\
Uni 3 & 127 & 18.6 \\
Uni 4 & 52 & 7.6 \\
Uni 5 & & \\
Year of enrolment & 218 & 32.0 \\
1st year & 301 & 44.1 \\
2nd year & 140 & 20.5 \\
3rd year & 23 & 3.4 \\
4th year & & \\
\hline
\end{tabular}

\subsection{DREEM scores by gender}

Three subscales revealed statistically significant differences between gender: Students' Academic Self-perception (females, $\mathrm{Md}=31$ vs. males, $\mathrm{Md}=32, \mathrm{U}=2.0, p=.043)$, Students' Perception of Atmosphere (females, Md $=42 \mathrm{vs}$. males, $\mathrm{Md}=43, \mathrm{U}=2.0, p=.002$ ) and Students' Social Self-perception (females, $\mathrm{Md}=26$ vs. males, $\mathrm{Md}=25$, $\mathrm{U}$ $=2.2, p=.028)$. The subscale: Students' Academic Selfperception included items such as: "I feel I am being well prepared for my profession" and "Last year's work has been a good preparation for this year's work" produced the highest median score in males $\mathrm{Md}=32$ (IQR = 29-34). The subscale Students' Perception of Atmosphere included items such as: Published by Sciedu Press
"The atmosphere is relaxed during lectures" and "I feel able to ask the questions I want" and again produced higher median scores in males $\mathrm{Md}=43$ (IQR $=41-45)$. Finally, the subscale Students' Social Self-perception produced higher median scores with females $\mathrm{Md}=26(\mathrm{IQR}=22-27)$.

A summary of median subscale scores and indication of significant differences by gender are presented in Table 2 .

\subsection{DREEM scores by age}

One subscale revealed statistically significant differences between age: Students' Social Self-perception (ages 35-39, Md $=22$ vs. ages $<20-24, \mathrm{Md}=26, \mathrm{Z}(5)=12.45, p<.029)$. The subscale Students' Social Self-perception included items such as: "There is a good support system for students who get stressed" and "I am rarely bored on this course" produced the highest median score $\mathrm{Md}=26(\mathrm{IQR}=22-27)$ in the age range $<20$ years and 20-24 years. A summary of median subscale scores and indication of significant differences by age level are presented in Table 3.

\subsection{DREEM scores by university}

All subscales revealed statistically significant differences between universities: Students' Perceptions of Learning (Uni $1, \mathrm{Md}=25$ vs. Uni 3, $\mathrm{Md}=49, \mathrm{Z}(3)=10.80, p=.015)$, Students' Perceptions of Teaching (Uni 1, Md $=25$ vs. Uni 3 and $5 \mathrm{Md}=49, \mathrm{Z}(3)=28.01, p<.001)$, Students' Academic Self-perception (Uni 1, Md = $30 \mathrm{vs.}$. Uni 2, 3 and 4 and 5 $\mathrm{Md}=31, \mathrm{Z}(3)=14.51, p=.019)$, Students' Perception of Atmosphere (Uni 3, Md = 41 vs. Uni 2 and $5 \mathrm{Md}=44, \mathrm{Z}(3)$ $=9.98, p=.002)$, Students' Social Self-perception (Uni 3, $\mathrm{Md}=24$ vs. Uni 2 and $5 \mathrm{Md}=26, \mathrm{Z}(3)=14.87, p<.001)$. The subscale: Students' Perceptions of Learning included items such as: "I am encouraged to participate in class" and produced the highest median score at Uni $3 \mathrm{Md}=49$ (IQR =43-52). The subscale: Students' Perceptions of Teaching included items such as: "The teachers are good at providing feedback to students" and "The teachers give clear examples" produced the highest median score at both Uni 3 and Uni 5 $\mathrm{Md}=39$ (IQR = 36-41). The subscale: Students' Academic Self-perception included items such as: "Much of what I have to learn seems relevant to a career in health sciences" produced the highest median score at Uni $5 \mathrm{Md}=32$ (IQR = 29-34). The subscale Students' Perception of Atmosphere included items such as: "The atmosphere motivates me as a learner" and "I feel able to ask the questions I want" produced higher median scores at Uni 2 and Uni $5 \mathrm{Md}=44$ $(I Q R=42-46)$. Finally, the subscale Students' Social Selfperception produced higher median scores at Uni 1 and Uni $5 \mathrm{Md}=27(\mathrm{IQR}=23-28)$.

A summary of median subscale scores and indication of significant differences by university are presented in Table 4 . 
Table 2. Median (Md) subscale and total DREEM scores by gender comparison

\begin{tabular}{lllll}
\hline Students' perception & Female Md(IQR) & Male Md(IQR) & Total Md(IQR) & Sig \\
\hline Students' perception of learning & $48(43-53)$ & $49(43-52)$ & $49(43-52)$ & $p<.001$ \\
Students' perception of teachers & $38(35-40)$ & $38(35-40)$ & $38(35-40)$ & $p=.00$ \\
Students' academic self-perception & $31(28-33)$ & $32(29-34)$ & $31(28-33)$ & $p=.04$ \\
Students' perception of atmosphere & $42(40-44)$ & $43(41-45)$ & $42(40-44)$ & $p=.00$ \\
Students' social self-perception & $26(22-27)$ & $25(21-26)$ & $26(22-27)$ & $p=.02$ \\
\hline
\end{tabular}

Table 3. Median (Md) subscale and total DREEM scores by age comparison

\begin{tabular}{|c|c|c|c|c|c|c|c|c|}
\hline $\begin{array}{l}\text { Students' } \\
\text { perception }\end{array}$ & $\begin{array}{l}<20 \text { years } \\
\text { Md (IQR) }\end{array}$ & $\begin{array}{l}\text { 20-24 years } \\
\text { Md (IQR) }\end{array}$ & $\begin{array}{l}\text { 25-29 years } \\
\text { Md (IQR) }\end{array}$ & $\begin{array}{l}\text { 30-34 years } \\
\text { Md (IQR) }\end{array}$ & $\begin{array}{l}\text { 35-39 years } \\
\text { Md (IQR) }\end{array}$ & $\begin{array}{l}\text { > } 40 \text { years } \\
\text { Md (IQR) }\end{array}$ & $\begin{array}{l}\text { Total } \\
\text { Md (IQR) }\end{array}$ & $p$ \\
\hline SPL & $\begin{array}{l}49 \\
(43-52)\end{array}$ & $\begin{array}{l}48 \\
(42-51)\end{array}$ & $\begin{array}{l}49 \\
(43-52)\end{array}$ & $\begin{array}{l}49 \\
(43-52)\end{array}$ & $\begin{array}{l}49 \\
(43-52)\end{array}$ & $\begin{array}{l}46 \\
(40-49)\end{array}$ & $\begin{array}{l}49 \\
(43-52)\end{array}$ & .52 \\
\hline SPT & $\begin{array}{l}38 \\
(35-40)\end{array}$ & $\begin{array}{l}38 \\
(35-40)\end{array}$ & $\begin{array}{l}39 \\
(36-41)\end{array}$ & $\begin{array}{l}36 \\
(33-37)\end{array}$ & $\begin{array}{l}36 \\
(33-37)\end{array}$ & $\begin{array}{l}36 \\
(33-37)\end{array}$ & $\begin{array}{l}38 \\
(35-40)\end{array}$ & .65 \\
\hline SAP & $\begin{array}{l}31 \\
(28-33)\end{array}$ & $\begin{array}{l}31 \\
(28-33)\end{array}$ & $\begin{array}{l}31 \\
(28-33)\end{array}$ & $\begin{array}{l}31 \\
(28-33)\end{array}$ & $\begin{array}{l}31 \\
(28-33)\end{array}$ & $\begin{array}{l}30 \\
(27-32)\end{array}$ & $\begin{array}{l}31 \\
(28-33)\end{array}$ & .51 \\
\hline SPA & $\begin{array}{l}42 \\
(40-44)\end{array}$ & $\begin{array}{l}43 \\
(41-44)\end{array}$ & $\begin{array}{l}43 \\
(41-44)\end{array}$ & $\begin{array}{l}41 \\
(39-43)\end{array}$ & $\begin{array}{l}41 \\
(39-43)\end{array}$ & $\begin{array}{l}43 \\
(41-44)\end{array}$ & $\begin{array}{l}42 \\
(40-44)\end{array}$ & .09 \\
\hline SSP & $\begin{array}{l}26 \\
(22-27)\end{array}$ & $\begin{array}{l}26 \\
(22-27)\end{array}$ & $\begin{array}{l}25 \\
(21-26)\end{array}$ & $\begin{array}{l}24 \\
(20-26)\end{array}$ & $\begin{array}{l}22 \\
(19-24)\end{array}$ & $\begin{array}{l}23 \\
(19-25)\end{array}$ & $\begin{array}{l}26 \\
(22-27)\end{array}$ & .02 \\
\hline
\end{tabular}

Note. SPL = Students' Perceptions of Learning; SPT = Students' Perceptions of Teaching; SAP = Students' Academic Self-perception; SPA = Students' Perception of Atmosphere; SSP = Students' Social Self-perception.

Table 4. Median (Md) subscale and total DREEM scores by university comparison

\begin{tabular}{llllllll}
\hline $\begin{array}{l}\text { Students' } \\
\text { perception }\end{array}$ & Uni 1 & Uni 2 & Uni 3 & Uni 4 & Uni 5 & Total \\
Md (IQR) & Md (IQR) & Md (IQR) & Md (IQR) & Md (IQR) & Md (IQR) & \multicolumn{1}{c}{} \\
\hline SPL & $45(38-47)$ & $46(39-48)$ & $49(43-52)$ & $48(42-51)$ & $48(42-51)$ & $49(43-52)$ & .01 \\
SPT & $36(33-38)$ & $38(35-40)$ & $39(36-41)$ & $37(34-39)$ & $39(36-41)$ & $38(35-40)$ & $<.001$ \\
SAP & $30(27-32)$ & $31(28-33)$ & $31(28-33)$ & $31(28-33)$ & $32(29-34)$ & $31(28-33)$ & .019 \\
SPA & $42(40-44)$ & $44(42-46)$ & $41(39-43)$ & $42(40-44)$ & $44(42-46)$ & $42(40-44)$ & .002 \\
SSP & $27(23-28)$ & $26(22-27)$ & $24(20-25)$ & $26(22-27)$ & $27(23-28)$ & $26(22-27)$ & .001 \\
\hline
\end{tabular}

Note. SPL = Students' Perceptions of Learning; SPT = Students' Perceptions of Teaching; SAP = Students' Academic Self-perception; SPA = Students' Perception of Atmosphere; SSP = Students' Social Self-perception.

Table 5. Median (Md) subscale and total DREEM scores by year Level comparison

\begin{tabular}{lllllll}
\hline \multirow{2}{*}{ Students' perception } & $\begin{array}{l}\text { 1st year } \\
\text { Md (IQR) }\end{array}$ & $\begin{array}{l}\text { 2nd year } \\
\text { Md (IQR) }\end{array}$ & $\begin{array}{l}\text { 3rd year } \\
\text { Md (IQR) }\end{array}$ & $\begin{array}{l}\text { 4th year } \\
\text { Md (IQR) }\end{array}$ & $\begin{array}{l}\text { Total } \\
\text { Md (IQR) }\end{array}$ & \multicolumn{1}{c}{ (IQR } \\
\hline SPL & $49(43-52)$ & $48(42-51)$ & $48(42-51)$ & $46(40-49)$ & $49(43-52)$ & .86 \\
SPT & $39(36-39)$ & $38(35-40)$ & $37(34-39)$ & $40(37-42)$ & $38(35-40)$ & .001 \\
SAP & $31(28-33)$ & $31(28-33)$ & $31(28-33)$ & $31(28-33)$ & $31(28-33)$ & .92 \\
SPA & $42(40-44)$ & $42(40-44)$ & $42(40-44)$ & $44(42-46)$ & $42(40-44)$ & .63 \\
SSP & $25(21-26)$ & $26(22-27)$ & $26(22-27)$ & $26(22-27)$ & $26(22-27)$ & .001 \\
\hline
\end{tabular}

Note. SPL = Students' Perceptions of Learning; SPT = Students' Perceptions of Teaching; SAP = Students' Academic Self-perception; SPA = Students' Perception of Atmosphere; SSP = Students' Social Self-perception.

\subsection{DREEM scores by year level}

Two subscales revealed statistically significant differences between student year levels: Students' Perceptions of Teaching 38
(Year 3, Md = 37 vs. Year $4 \mathrm{Md}=40, \mathrm{Z}(3)=17.14, p=.001$ ) and Students' Social Self-perception (Year $1, \mathrm{Md}=25 \mathrm{vs}$. Year 2-4 Md = 26, Z(3) = 14.45, $p<.0001)$. The subscale Stu- 
dents' Perceptions of Teaching included items such as: "The teachers provide constructive criticism here", "The teachers have good communication skills with patients/clients" and "The teachers are knowledgeable" produced the highest median score in final year $\mathrm{Md}=40(\mathrm{IQR}=37-42)$ and lowest in second year Md = 38 (IQR = 35-40). The subscale Students' Social Self-perception included items such as: "There is a good support system for students who get stressed", "My accommodation is pleasant" and "My social life is good" produced the lowest median score $\mathrm{Md}=25$ (IQR = 21-26) in year one compared with the remaining three years of study.

A summary of median subscale scores and indication of significant differences by year level are presented in Table 5.

\section{Discussion}

The aim of this study was to evaluate the education environment, as perceived by paramedicine students in Australia and New Zealand, and determine whether there are aspects of the education environment that are perceived more or less positively amongst students from different institutions, year level, age or gender. The DREEM has been shown to be valid and reliable to make comparison of students' perceptions of the educational environment. ${ }^{[16,20]}$ The DREEM can be used to assess very specific issues relation to each of the subscales and is a quick instrument compared with qualitative interviews. ${ }^{[21]}$ Paramedicine students from different universities reported statistically significant differences in their perceptions of the education environment. A number of sub-scales reached statistical significance and are worthy of further discussion and consideration, in particular in relation to gender, age, student year level and university.

\subsection{Perception of the learning environment by gender}

Statistically significant differences were identified between genders with female students reporting less satisfaction with the learning and general atmosphere at university, and generally were more critical about their academic abilities. On the other hand, female students reported being more satisfied with the social aspects of the educational environment than male students. Differences in gender perception is consistent with other educational research using the DREEM questionnaire ${ }^{[19,22,23]}$ and perhaps indicates differences between male and female students in their learning styles and perceptions of the education environment. In a 2011 study of eight different healthcare disciplines Brown et al. found that female students in general had a higher DREEM scores overall compared to male peers (138.8vs. 132.3, $p=.002) .{ }^{[22]}$ This is in contrast to our findings. The only similarity the current study has with Brown et al. in regards to gender (26 vs. 25, $p=$ $.028)$, was that females students were more satisfied in their social self-perceptions compared to male peers (19.2 vs. 18.2, $p=.009)$. Similar to the results from Brown et al., ${ }^{[22]}$ a study by Dunne et al. ${ }^{[23]}$ observed that female medical students had more positive views overall compared to males (126 vs. $123, p<.05)$. Significant $(p<.05)$ differences in perception of teachers and perception of atmosphere were noted with females scoring higher on both accounts. It is important to understand the impact of gender in paramedicine, including the emotional dimension of paramedic practice. ${ }^{[24,25]}$ This finding offers opportunities for paramedic educators to develop curriculum that explores the value of emotional work as part of the paramedicine education environment.

\subsection{Perception of the learning environment by age}

There were statistically significant differences reported between age groups for one subscale: Students' Social Selfperception (SSP). In this study, older students were generally less satisfied with their social life than their younger peers, which is consistent with differences between age groups of healthcare students has been identified in other research ${ }^{\text {[22] }}$ and more broadly in the higher education sector. ${ }^{[26-28]}$ In a study of osteopathy students by Vaughan et al., slight but statistically significant differences were found between age and 7 individual items. ${ }^{[29]}$ Two of these items were from the SSP subscale: "I have good friends in this course" $(r=-0.17$, $p<.01)$ and "My social life is good" $(r=-0.15, p<.05)$, however, Vaughan et al. found no significant differences between DREEM or any of the subscales. ${ }^{[29]}$ Brown et al. discovered that health care students who did not enrol in their tertiary education directly from school had a higher regard of their learning environment compared to those who came to university directly from school (139.1 vs. $135.9, p=.043) .{ }^{[22]}$ This result was the same across all subscales, however, only the perceptions of atmosphere subscale reached statistical significance. Significant factors that influence mature-aged student experiences may include variations in maturity levels, life experiences and previous education, differences in learning styles and experiences with technology and older students may have different financial and family responsibilities to younger students. ${ }^{[2]}$ Of course, there are advantages with being an older student because in paramedicine, younger students have sometimes been perceived as "too young" and older students are perceived as having more maturity and experience. $^{[22]}$

\subsection{Perception of the learning environment by univer- sity}

Statistically significant differences between universities were identified in all subscales. Uni 1 had the lowest score on three factors (learning, teaching, academic perception) and Uni 3 had two factors (atmosphere, personal life) with the lowest 
scores. These differences are not surprising considering the differences between the ways that universities structure their paramedicine programs. For example, the student cohort sizes (this ranges from 60-300) the number of hours of clinical placement and the timing of clinical placements. The DREEM has been used by other researchers to compare student perceptions of the strengths and weaknesses of curricula and learning environment at different institutions. ${ }^{[20,30]}$ In a study of the differences between two universities from two different countries Roff et al. ${ }^{[20]}$ found that Nigerian medical students had significantly lower DREEM scores in subscales perception of atmosphere (26.95 vs. 32.24, $p<.05)$ and social self-perception $(12.68 v s .17 .57, p<.05)$ compared to Nepalese medical students. In another study of two universities from Saudi Arabia, Zawawi and Elzubeir ${ }^{[30]}$ discovered significant differences both overall (100 vs. 131, $p=.000)$ and in separate subscales: learning (23.18 vs. 36.44, $p=$ $.000)$, self-perception (13.51 vs. 19.81, $p=.000)$ and atmosphere (24.66 vs. 32.77, $p=.000)$. These two universities are employing very different teaching strategies and the study by Zawawi and Elzubeir shows that one of those strategies clearly outperforms the other in terms of student perception. ${ }^{[30]}$ Since our results show significant differences between universities it would be beneficial to further investigate these differences in order to understand what contributes to the perceived strengths and weaknesses of curricula and identify areas in need of intervention. While some differences would be expected, further examination would be important particularly around the student preparation of clinical placements. For example, should each university teach the same clinical skills and knowledge throughout their programs at the same year level? Furthermore, should a collaborative 'preparation for clinical placement' seminar/program be implemented in all universities? These are important questions to be addressed.

\subsection{Perception of the learning environment by year level}

Two of the five subscales revealed statistically significant differences between year level data: year 4 students had the highest scores for their perception of teaching (SPT-factor 2 ), and year 1 students were the least satisfied with their social life (SSP-factor 5). It may be that by their fourth year, students are more satisfied with their experience of the educational environment as they prepare for the transition to the workforce. On the other hand, it would seem that year 1 students are generally happy and enjoying life at university, however they are noticing the effects of the educational environment on their social life. Other writers ${ }^{[19,20,22]}$ have observed these differences between year level cohorts and used the findings as an opportunity to review the institution's orientation, curriculum and to guide strategic planning students across their educational experience. In a study of Canadian chiropractic students it was revealed that as students became more senior the average scores in each subscale decreased considerably with 44 out of 50 items indicating statistically significant results. ${ }^{[19]}$ In a study of undergraduates from eight health disciplines Brown et al. revealed that the average DREEM scores peaked in second year before dropping again in the later year levels with forth year students generally having the lowest responses (136.0 vs. 141.6 vs. 138.1 vs. $135.0, p=.026) .{ }^{[22]}$ These are significant findings that warrant further research to explore the connections between curriculum and student expectations across year levels. There is the suggestion of an association between the DREEM score and academic achievement, which means that the DREEM and can be used as an indicator to identify students who are likely to have high academic achievement and those at risk of poorer academic performance. ${ }^{[17]}$ In addition, the DREEM is an effective diagnostic tool to identify areas of concern and inform strategic planning and curriculum development. ${ }^{[19]}$

\subsection{Limitations}

Whilst this study provides valuable insight into the perceptions of the education environment by paramedicine students, there are some limitations that should be acknowledged. Firstly, there is the potential impact of inconsistent structures at the various institutions when interpreting year level and university data. Some students might have been enrolled in a double degree (e.g., Nursing and Paramedicine), or be enrolled in a conversion program (e.g., experienced paramedic who is converting to a paramedicine qualification). In addition, there is much variation between universities about the timing of clinical education. Some students do clinical placements in year 1 and other students do the majority of their placement hours in years 3 and 4 . We are unable to tell if year 3 students are in their final year of study, or not. It is not known if paramedicine students' perception of the education environment changes with exposure to the clinical practice environment and this is an opportunity for further research. Secondly, the number of students varied considerably between institutions and year level. It is difficult to gauge the impact this has on scores for each study. Finally, convenience sampling was used to recruit participants and no follow ups were conducted. This may have affected results as those students who were present on the day that the researcher visited may have been students who were more engaged and satisfied with the educational environment than those who were not there.

To the best of our knowledge is the first reported paramedicine clinical placement benchmarking study involv- 
ing two countries. The study provides a new body of work in this area and supports existing work on this critical component of paramedicine education. Results of this study provide university providers and the relevant stakeholders such as ambulance services and peak bodies with some a clearer picture of students' perceptions of their placement. Further research should now extend these findings and include more universities and include data from paramedic instructors (preceptors) and staff from ambulance services, peak bodies and professional associations. This further research should then provide more evidence on what constitutes a quality clinical placement, and what responsibilities are held by all participating parties.

\section{Conclusion}

This study has investigated the education environment as perceived by paramedicine students in Victoria, Australia and Auckland, New Zealand and found that generally, stu- dents are satisfied with the education environment at their institution. The DREEM questionnaire has highlighted significant differences between universities, which is not surprising considering the various ways that universities structure their paramedicine programs. These findings can be used to inform universities and ambulance services about these differences and to guide strategic planning to ensure that there is a more consistent approach to paramedicine education in Australia and New Zealand.

\section{ACKNOWLEDGeMENTS}

This work was supported by Health Workforce Australia. This research is part of a larger study titled: "Paramedicine clinical placement duration and quality variance: An international benchmarking study". ${ }^{[7]}$

\section{CONFlicts OF InTEREST Disclosure}

The authors declare that there is no conflict of interest statement.

\section{REFERENCES}

[1] Joyce C, et al. Trends in the paramedic workforce: a profession in transition. Australian Health Review. 2009; 33(4): 533-540. http://dx.doi.org/10.1071/AH090533

[2] Waxman A, Williams B. Paramedic pre-employment education and the concerns of our future: What are our expectations? Journal of Emergency Primary Health Care. 2006; 4(4).

[3] Williams B, Onsman A, Brown T. Establishing paramedic graduate attributes: Design and validation of a paramedic graduate attribute scale. Evaluation for the Health Professions. 2012; 35 (2): 148168. PMid:21613243 http://dx.doi.org/10.1177/016327871 1407314

[4] Williams B, Onsman A, Brown T. Is the Australian Paramedic Discipline a Profession? A National Perspective International Paramedic Practice. 2012; 1(5): 161-168. http://dx.doi.org/10.12968/ ippr.2012.1.5.161

[5] Council of Ambulance Authorities. Guidelines for the Assessment and Accreditation of Entry-level Paramedic Education Programs. 2010. Council of Ambulance Authorities.

[6] Hou X, Rego J, Service M. Review article: Paramedic education opportunities and challenges in Australia. Emergency Medicine Australasia. 2013; 25: 114-119. PMid:23560960 http://dx.doi.org $/ 10.1111 / 1742-6723.12034$

[7] O'Meara P, et al. Paramedic clinical placement duration and quality variance: An international benchmarking study. Health Workforce Australia: Health Workforce Australia. 2014.

[8] O'Meara P, Hickson H, Huggins C. Starting the conversation: What are the issues for Paramedic student clinical education. Australasian Journal of Paramedicine. 2014; 11(4).

[9] Williams B, Brown T, Winship C. The mismatch between perceived and preferred expectations of undergraduate paramedic students. The Internet Journal of Allied Health Sciences and Practice. 2012; 10(4): $1-8$.

Published by Sciedu Press
[10] Lord B, McCall L, Wray N. Factors affecting the education of preemployment paramedic students during the clinical practicum. Journal of Emergency Primary Health Care. 2012; 7(4).

[11] Boyle M, Williams B, Burgess S. Contemporary simulation education for undergraduate paramedic students. Emerg Med J. 2007; 24(12): 854-7. PMid:18029524 http://dx.doi.org/10.1136/emj . 200 7.046318

[12] Boyle M, et al. Ambulance clinical placements-A pilot study of students' experience. BMC Medical Education. 2008; 8(1): 19. PMid:18400111 http://dx.doi.org/10.1186/1472-692 0-8-19

[13] Ross L, et al. Students' views of teachers using the Clinical Teaching Effectiveness Inventory. Journal of Paramedic Practice. 2013; 5(6): 336-340. http://dx.doi.org/10.12968/jpar.2013.5.6.336

[14] Williams B, Brown T, Archer F. Can DVD simulations provide an effective alternative for paramedic clinical placement education? Emergency Medicine Journal. 2009; 26(5): 377-381. PMid:19386881 http://dx.doi.org/10.1136/emj.2008.060723

[15] Williams B, et al. Can multidisciplinary clinical DVD simulations transform clinical fieldwork education for paramedic, occupational therapy, physiotherapy, and nursing students? Journal of Allied Health. 2010; 39(1): 3-10. PMid:20217001

[16] Roff S, et al. Development and validation of the Dundee Ready Education Environment Measure (DREEM). Medical Teacher. 1997; 19(4): 295-299. http://dx.doi.org/10.3109/0142159970903 4208

[17] Roff S. The Dundee Ready Educational Environment Measure (DREEM) - a generic instrument for measuring students' perceptions of undergraduate health professions curricula. Medical Teacher. 2005; 27(4): 322-325. PMid:16024414 http://dx.doi.org/10. 1080/01421590500151054

[18] Miles S, Swift L, Leinster SJ. The Dundee Ready Education Environment Measure (DREEM): A review of its adoption and use. 
Medical Teacher. 2012; 34(9): e620-e634. PMid:22471916 http: //dx.doi.org/10.3109/0142159x.2012.668625

[19] Till H. Identifying the perceived weaknesses of a new curriculum by means of the Dundee Ready Education Environment Measure (DREEM) Inventory. Medical Teacher. 2004; 26(1): 3945. PMid:14744693 http://dx.doi.org/10.1080/014215903 10001642948

[20] Roff S, et al. A global diagnostic tool for measuring educational environment: comparing Nigeria and Nepal. Medical Teacher. 2001; 23(4): 378-382. PMid:12098385 http://dx.doi.org/10.1080 /01421590120043080

[21] Denz-Penhey H, Murdoch JC. A comparison between findings from the DREEM questionnaire and that from qualitative interviews. Medical Teacher. 2009; 31(10): e449-e453. PMid:19877851 http://dx.doi.org/10.3109/01421590902849552

[22] Brown T, Williams B, Lynch M. The Australian DREEM: evaluating student perceptions of academic learning environments within eight health science courses. Int J Med Educ. 2011; 2: 94-101. http://dx.doi.org/10.5116/ijme.4e66.1b37

[23] Dunne F, McAleer S, Roff S. Assessment of the undergraduate medical education environment in a large UK medical school. Health Education Journal. 2006; 65(2): 149-158. http://dx.doi.org/1 $0.1177 / 001789690606500205$

[24] Williams A. Emotion work in paramedic practice: The implications for nurse educators. Nurse Education Today. 2012; 32(4): 368372. PMid:21640449 http://dx.doi.org/10.1016/j.nedt. 20 11.05 .008
[25] Williams A. The strategies used to deal with emotion work in student paramedic practice. Nurse Education in Practice. 2013; 13(3): 207-212. PMid:23083896 http://dx.doi .org/10.1016/j.nep r.2012.09.010

[26] Jones C, et al. Net generation or Digital Natives: Is there a distinct new generation entering university? Computers \& Education 2010; 54(3): 722-732. http://dx.doi.org/10.1016/j.compe du. 2009.09. 022

[27] Kenny A, et al. Mature age students access, entry and success in nurse education: An action research study. Contemporary Nurse, 2011; 38(1-2): 106-118. PMid:21854242 http://dx.doi .org/1 $0.5172 /$ conu. $2011.38 .1-2.106$

[28] McCune V, et al. Mature and younger students' reasons for making the transition from further education into higher education. Teaching in Higher Education. 2010; 15(6): 691-702. http://dx. doi.org $/ 10.1080 / 13562517.2010 .507303$

[29] Vaughan B, et al. The DREEM, part 1: measurement of the educational environment in an osteopathy teaching program. BMC Medical Education. 2014; 14(1). http://dx.doi .org/10.1186/1472-6 920-14-99

[30] Zawawi A, Elzubeir M. Using DREEM to compare graduating students' perceptions of learning environments at medical schools adopting contrasting educational strategies. Medical Teacher. 2012. 34(s1): S25-S31. PMid:22409187 http://dx.doi.org/10.3109/01421 59X.2012.656747 